УДК 316

$10.17213 / 2075-2067-2021-1-53-63$

\title{
РЕСУРСЫ ОНЛАЙН-ОБУЧЕНИЯ ПО ОБЕСПЕЧЕНИЮ КАЧЕСТВА ВЫСШЕГО ОБРАЗОВАНИЯ ${ }^{1}$
}

\author{
(C) 2021 г. А. В. Лацвеева
}

\section{Южно-Российский государственный политехнический университет (НПИ) имени М. И. Платова, г. Новочеркасск, Россия}

Цель исследования заключается в изучении ресурсов онлайн-обучения в обеспечении качества высшего образования.

Методология исследования базируется на современных междисииплинарных исследованиях сферы высшего образования и основных идеях современной сочиологии образования.

Результаты исследования. Оиенка ресурсов онлайн-обучения в контексте их использования как возможностей достижения качества высшего образования позволила выделить три направления, в рамках которых имеются принциииальные различия, имеющие следующчие проявления: 1) приемлемое качество высшего образования можно обеспечить в режиме онлайн-обучения уже сейчас; 2) качество образования можно обеспечить в будущем при решении ряда проблемных вопросов, возникающих в настоящее время в ходе образовательного процесса при онлайн-обучении; 3) качество обучения в режиме онлайн уступает классическому, т.к. имеет ограниченный объем ресурсов.

Дальнейшие перспективы исследования. Несмотря на широкую представленность проблемы большим количеством подходов и направлений, она содержит цельий ряд лакун, без заполнения которых невозможно решить вопрос о ресурсах онлайн-обучения в достижении качества образования в высшей школе. Прежде всего, это отсутствие внятной дефиниции онлайн-обучения, недостаточно ясное понимание того, на какие виды оно распадается в реальных образовательных практиках и на каком уровне качества эти виды онлайн-обучения способны поддерживать образовательный проиесс в высшей школе.

Ключевые слова: онлайн-обучение; качество высшего образования; иңифровизация; массовые открытые онлайн-курсы.

\section{ONLINE LEARNING RESOURCES FOR QUALITY ASSURANCE OF HIGHER EDUCATION}

\section{(C) 2021 A. V. Latsveeva}

\section{Platov South Russian State Polytechnic University (NPI), Novocherkassk, Russia}

The purpose of the study is to study the resources of online learning in ensuring the quality of higher education.

1 Статья выполнена в рамках реализации гранта Президента Российской Федерации для государственной поддержки ведущих научных школ Российской Федерации (НШ-2582.2020.6) на тему «Государственная политика в сфере высшего образования и развитие инновационного потенциала молодежи: экономические и неэкономические детерминанты и механизмы в условиях регионализации социального пространства и становления Индустрии 4.0». 
The research methodology is based on modern interdisciplinary research in the field of higher education and the main ideas of modern sociology of education.

The results of the study. The assessment of online learning resources in the context of their use as opportunities to achieve the quality of higher education allowed us to identify three areas in which there are fundamental differences, which have the following manifestations: 1) acceptable quality of higher education can provide online training now; 2) the quality of education can be provided in the future for solving a number of problems arising in the present time during the educational process in online learning; 3) the quality of online learning inferior to the classic, because it has a limited amount of resources.

The prospects for further research. Despite the wide representation of the problem by a large number of approaches and directions, it contains a number of gaps, without filling which it is impossible to solve the issue of online learning resources in achieving the quality of education in higher education. First of all, this is the lack of a clear definition of online learning, a lack of a clear understanding of what types it breaks down into in real educational practices and at what level of quality these types of online learning are able to support the educational process in higher education.

Key words: online learning; quality of higher education; digitalization; mass open online courses.

Введение. Онлайн-обучение относится к числу тех редких тем, по которым написаны сотни работ. До 2012 г. российские социологи и представители других общественных наук крайне редко писали труды по заявленной проблематике, но эта дата для возникновения интереса к оценке ресурсов онлайн-обучения по обеспечению качества высшего образования в некотором роде становится рубежной. В том году в США реализуется идея, получившая практическое воплощение в так называемых массовых открытых онлайн-курcax (МООК). Первыми из них стали Coursera, MTx и Udacity [1]. Эксперимент был признан удачным, и далее в большом количестве начали возникать действующие по схожим принципам образовательные платформы [2]. Это породило в обществе большой ажиотаж, на который наука не могла не откликнуться. Во всем мире начинает складываться многослойное дискурсивное пространство, сформированное из самых разнообразных тематических аспектов: понятие онлайн-обучения, его виды, инструментальные и содержательные возможности, мотивация обучаемых и педагогов и т.п. $[3,4,5]$.

Обзор исследовательской литературы. В отечественной социологии до определенного момента интерес к данному вопро- су поддерживался незначительный. Можно выделить работы, написанные С.Л. Тимкиным, А. А. Андреевым и В.И. Солдаткиным, Д. Бадарч, Н. Г. Токаревой и М.С. Цветковой, М.П. Лапчик [6-11], в которых отстаивалась идея замены классического университета электронным на платформе МООК. В целом же российское научное сообщество новую образовательную модель не приняло, встретив ее или индифферентно, или критически [12]. Однако уже в 2016 г. ситуация меняется радикально. 25 октября указанного года Президент РФ подписал протокол Паспорта «Современная цифровая образовательная среда в Российской Федерации», на основании которого была принята дорожная карта о поэтапном в течение 2016-2021 гг. внедрении в образовательное пространство России онлайн-курсов с расчетом, чтобы к 2026 г. численность студентов, проходящих обучение дистанционно, возросла до 11 млн. [13]. С этого момента ректораты российских вузов инициируют в возглавляемых ими высших учебных заведениях разработку собственных онлайн-курсов, содействуют сотрудничеству с ведущими мировыми и российскими платформами МООК, пытаются встроиться в структуру мирового рынка электронного образования. Ученое сообщество немедлен- 
но откликается на эти процессы большим количеством публикаций, где благодаря нормативной легитимации в указанном выше документе впервые начинает доминировать термин «онлайн-образование», вытесняя собой более типичные для предыдущего этапа развития дискурса понятия «дистанционное образование» и «электронное обучение». Но настоящий всплеск интереса к анализируемой проблеме состоялся лишь в 2020 г., когда весь мир, включая Россию, вынужденно перешел на онлайн-обучение из-за пандемии.

Результаты исследования. Далее перейдем к оценке ресурсов онлайн-обучения в обеспечении качества образования в высшей школе. Различия в сложившемся дискурсе по данному вопросу весьма незначительны. Наиболее существенное значение имеет личное отношение исследователя к перспективам онлайн-обучения в институте высшего образования, поэтому рассмотрим данный аспект с точки зрения принятия или отрицания специалистами этой формы организации образовательного процесса. Выделим три основных подхода в отношении онлайн-обучения: 1) приемлемое качество высшего образования с помощью онлайн можно обеспечить уже сейчас; 2) качество можно обеспечить в будущем при решении ряда проблемных вопросов образовательного процесса при онлайн-обучении; 3) качество обучения онлайн уступает классическому, т. к. имеет ограниченный объем ресурсов.

1. Приемлемое качество высшего образования можно обеспечить в режиме онлайн-обучения уже сейчас. Позиция сторонников онлайн-обучения нередко обосновывается возникшими различиями между обучаемыми и учителями в эпоху информационных технологий. Так, Д.В. Гуль убежден, что для обеспечения качества образования современной молодежи вовсе не требуется всем привычное «образовательное пространство», т.к. она «...уже привыкла к размытости рамок понятия "присутствие" и к параллельному “присутствию” в нескольких жизненных пространствах» [14, с. 101]. Иными словами, молодежь уже сейчас готова учиться самостоятельно, не будучи погруженной в образовательную среду, отведенную специально для образовательной деятельности. Эта убежденность подкрепляется ресурсами обеспечения качества, которыми являются обучающие программы, тестирование, сетевая коммуникация с преподавателем и другими студентами, интерактивные доски, консультации и т.п.

Т.Ф. Кряклина и С.В. Реттих подходят к вопросу с тех же позиций, что и Д.В. Гуль, объясняя необходимость и даже неизбежность онлайн-обучения трансформационными процессами, произошедшими в способах коммуникации у молодежи в последнее десятилетие. Они называют ее «аборигенами цифрового мира». Отсюда вывод: в ходе сетевого обучения студенты чувствуют себя более комфортно и лучше способны воспринимать информацию, чем на занятиях в аудитории. Помимо общей идеи, собственно достижение качества обосновывается несколькими ресурсными возможностями. На первом месте стоит технический компонент: интерактивные доски, использование разработанных именно под определенную специальность программ обучения и т.п. К методическим ресурсам авторы относят грамотно разработанную структуру курса, доступность, удобство использования. Кроме этого, упоминаются гибкий учебный график, который учащиеся организуют самостоятельно, и объективная оценка знаний со стороны преподавателей. Эффективность указанных ресурсов ставится в зависимость от способности студента к самоорганизации и наличия у него внутренней мотивации [15].

А.А. Смирнова обращает внимание на относительность такой категории, как качество образования. Если принимать в расчет, что онлайн-курсы широко распространяются именно западными университетами, то даже их ухудшенный электронный формат объективно дает более качественное образование, чем низкостатусные региональные вузы. Помимо этого категория качества обосновывается тем, что в условиях онлайн-обучения развивается новый вид цифровой компетенции - кооперация в сетевых сообществах, что намного важнее, чем дисциплина и конкурентность, развиваемые в процессе обучения в очной форме [16].

Н. В. Гречушкина связывает возможности достижения качества образования с изменением идеологии, в которой работает высшая 
школа. Если ранее основой образования считалось воспроизводство фундаментального знания и соответствующее обучение будущего специалиста, то сейчас весь образовательный процесс сводится к формированию набора компетенций. Компетентностный подход органично сочетается с электронным обучением, т.к. с ним связывается поверхностное и фрагментарное овладение информацией. Гарантии качества в обозначенных границах обеспечиваются структурированностью МООК, асинхронностью, возможностью вернуться в любой момент к пройденному контенту, индивидуальной траекторией обучения, преобладанием самообразования, преодолением субъективизма преподавателей, инновационностью курсов, развитием адекватной самооценки и рефлексивности [17].

2. Качество образования можно обеспечить в будущем при решении ряда проблемных вопросов, возникающих в настоящее время в ходе образовательного процесса при онлайн-обучении. А.В. Базылевич пишет о неизбежности распространения онлайн-обучения во всем мире. В этот процесс активно включились ведущие западные университеты, которые предлагают электронные образовательные пакеты с оформлением контракта на коммерческое обучение или размещают свои МООК на образовательных платформах. Российские университеты также должны включиться в этот поток, чтобы обеспечивать возникающие потребности молодежи.

В то же время автор отмечает, что ценность действующего онлайн-обучения снижается из-за двух проблем. Во-первых, появляется большое количество низкокачественных онлайн-курсов, которые не содержат ценной образовательной информации. А.В. Базылевич настаивает на необходимости обязательной государственной сертификации организаций, предлагающих электронный контент. Это может предоставить хотя бы рамочные гарантии качества. Во-вторых, современных игроков на рынке онлайн-обучения крайне мало беспокоит, что получает обучающийся по итогам прохождения онлайн-курсов. Сертификаты об окончании курса выдаются всем желающим, которые формально его закончили. Реальных оценок качества образования, кроме тестов, не существует, а тесты очень часто проходят с нарушением корректности их заполнения [18].

Я.М. Рощина, С.Ю. Рощин и В.Н. Рудаков, опираясь на авторское эмпирическое исследование, указывают на два доминирующих аспекта качества, на которые ссылаются сторонники онлайн-обучения: доступность и индивидуализация. Однако указанные авторы ценность этих компонентов качества признают только в отношении общих дисциплин, исключая из списка допустимых перевод в режим-онлайн предметы по специальности. Это обосновывается отсутствием достаточной для качественного обучения обратной связи с преподавателем, угасанием необходимых стимулов к образованию при снижении пресса внешнего контроля и невозможностью обеспечить идентичность личности учащегося во время выполнения учебных операций. Ряд подобных препятствий исследователи предлагают решать технологически. Например, вводить систему прокторинга, чтобы предотвратить нечестное поведение. Еще одна мера состоит в детальной регламентации самостоятельной работы. В целом же авторы приходят к выводу о необходимости создания смешанной модели обучения, где будут сочетаться принципы классического и электронного обучения [19].

Ю.Л. Костюк и его соавторы выделяют факторы, препятствующие качеству образования в режиме МООК и одновременно предлагают меры, направленные на решение выявленных проблем. Отмечается, что овладение основами теории и механизмом применения ее на практике - это универсальная трудность, которая актуальна не только для онлайн-обучения, но и традиционного. При этом подчеркивается, что без «человеческих ресурсов» (читай - преподавателей) данную трудность не решить. Констатируется, что в формате онлайн такого объема человеческих ресурсов нет. Решение предлагается парадоксальное: автоматизировать образовательный процесс. Подобная мера находится в явном противоречии с исходными позициями. Еще одну трудность в достижении качества видят в том, что у преподавателя нет достаточного объема времени, чтобы проверить все эссе в условиях большого количества обучающихся. В целях решения проблемы 
выдвигается предложение доверить проверку самим же слушателям. Это означает, что учить учащихся будут обучающиеся. Третья сложность - обязательность учета того, что у студентов разный уровень способностей. В традиционной модели преподаватели стараются дифференцировать сложность заданий, соизмеряя ее с потенциалом студента. Электронный контент по своей природе формализован, и в него в принципе нельзя заложить дифференцированный подход. Данное затруднение предлагается решать посредством специального тестирования обучающихся, результаты которого будут использоваться при распределении нагрузки [20].

Н.А. Ольшанникова не видит больших перспектив у электронного обучения как альтернативы классического. Ученый называет видео-лекции образовательным суррогатом, а прилагающийся к ним контент - плохо структурированной траекторией индивидуального самообразования. Однако даже в таком режиме отрицания обнаруживается важный сюжет выхода на категорию качества в позитивном аспекте. Автор отмечает, что значительная роль МООК состоит в решении проблем профессиональной переквалификации. Это актуально и важно в современном мире, где стремительно создаются новые профессии и возникает потребность в их овладении. Коммерческое онлайн-обучение вполне способно выполнить функцию обучения новым профессиям или совершенствования навыков в рамках уже обученным [21].

$\mathrm{B}$ соответствии с позицией С. К. Ибодовой, у онлайн-образования есть достаточное количество ресурсов, способных обеспечить высокий уровень качества в процессе обучения. К их числу относятся следующие преимущества: лучшая запоминаемость информации по сравнению с традиционным типом обучения; меньший объем временных затрат вследствие более рационального использования времени; наличие стимула к развитию самостоятельности в процессе поиска и запоминания информации; поддержка удобного темпа, что становится возможным благодаря выбору индивидуальных траекторий в учебной деятельности. Однако эти преимущества сводятся на нет из-за недостатков, свойственных электронному обучению. К ним относятся: неравенство возможностей в получении доступа к определенным видам электронного контента (например, учиться в иностранных вузах онлайн могут только те студенты, кто в совершенстве знает английский язык); возникновение социальной изоляции, разрушение привычных социальных групп и общностей, их замена на сетевые сообщества; невозможность организации практических занятий в таком же полноценном качестве, как в традиционном обучении; низкий уровень мотивации и концентрации на обучение у большинства студентов, что находит подтверждение в неспособности большинства обучающихся пройти электронное обучение до конца (более 90\%); резкое снижение контроля за обучением молодых людей (родители контролировать не в состоянии, а преподаватели в классическом понимании отсутствуют). Пока эти недостатки не окажутся преодоленными, говорить о замене классического обучения электронным или даже позиционировании его в качестве альтернативного, преждевременно [22]. Эти же аргументы перечисляет и Т.М. Гулая, которая помимо сказанного обращает внимание на слабую корреляцию между массовостью МООК, что заложено в самом их названии, с возможностями обеспечения качества образования [23].

Последовательным сторонником онлайнобучения следует назвать Н.В. Кузнецова. Однако стоит отметить, что ни в одной из работ, где он является автором или соавтором, не приводятся аргументы, подтверждающие необходимость перевода образовательного процесса в электронный формат. Данная проблема ставится в более широкий контекст — цифровизации экономики и конкурентного взаимодействия на этой нише с другими странами [24]. Но подобный аргумент едва ли можно признать убедительным, т.к. автор не раскрывает главного: «как цифровизация может улучшить качество образования?». В то же время Н.В. Кузнецов делает убедительный анализ того, почему в текущий момент полный перевод высшей школы в цифровой формат приведет к ухудшению качества образования. В числе причин он называет следующие: низкий уровень развития цифровой инфраструктуры в вузах; неготовность самих преподавателей работать в циф- 
ровой среде из-за «старения» кадров; отрицание со стороны большинства студентов преимуществ онлайн-образования по сравнению с классическим образованием, а также их низкий уровень мотивации к обучению в целом. Исследователь приходит к убеждению, что на данном этапе наиболее оптимальным вариантом было бы смешанное обучение, в котором формат онлайн выступал бы дополнением к традиционному. Однако будущее, по его мнению, даже не за МООК в их современном виде и не за коммерческими онлайн-курсами, а за внедрением программ искусственного интеллекта и полной автоматизации всего образовательного процесса [25].

\section{3. Качество обучения в режиме онлайн} уступает классическому, т.к. имеет ограниченный объем ресурсов. Долгое время труды об онлайн-обучении писали только его приверженцы, что объясняется индифферентностью большинства преподавателей к электронному обучению или даже открытой враждебностью к нему из-за опасений потерять работу. С наступлением 2020 г. и обретением фактически всем преподавательским сообществом практики работы в режиме онлайн стали появляться и крайне отрицательные сочинения по данной проблематике.

Так, В.В. Касьянов, С.И. Самыгин и К.С. Мухина пишут о депрофессионализации студентов в ходе их обучения в цифровой среде. Отмечается, что высшее образование нельзя свести к процессу передачи информации. «Это дискуссии, конкуренция и сотрудничество - то есть выработка определенных социальных навыков, это возможность делиться опытом и завязывать контакты, которые, возможно, потом будут играть определяющую роль в профессиональной карьере» [26, с. 56]. Онлайн существенно снижает возможности передачи практических знаний, а то и препятствует этому полностью. Режим самоизоляции позволил посмотреть на электронное обучение и с другой, совершенно неожиданной стороны. Одно дело ратовать за него в теории, и совсем другое - получить массовый практический опыт. Многие из преподавателей стали жаловаться на повышенную утомляемость, отсутствие очень важной для корректировки образовательного процесса невербальной коммуникации, затруднения в получении обратной связи, деформацию аудитории как реальной группы. Неизученным является также и такой аспект, как ликвидация личности преподавателя и студента. Это пагубно сказывается не только на процессе воспитания, что очевидно, но и на процессе обучения, который всегда поддерживался через личностное начало. В. В. Ковалев, А.В. Дятлова и К. В. Воденко изучали ресурсные возможности онлайн-обучения с применением метода фокусированных интервью в студенческих группах. Социологи предложили студентам для оценки несколько индикаторов: четыре по качеству обучения («овладение знаниями, умениями и навыками», «приобретение опыта практической деятельности», «развитие способностей», «формирование у обучающихся мотивации») и пять для оценки возможности интеллектуально развиваться («сообразительность», «восприимчивость», «любознательность», «вербализация», «эрудиция») [27]. Полемику вызвал только один индикатор, связанный с мотивацией. Сторонники онлайн-обучения были убеждены, что заинтересованность в учебе возникает лишь при наличии внутренних импульсов, что внешняя мотивация со стороны преподавателей не играет заметной роли. При всей спорности подобного суждения куда более важное значение имеет то, что практически все студенты, принявшие участие в исследовании, не увидели у электронного обучения ресурсов, способствующих образованию личности студента в большей степени, чем просто как процесс односторонней передачи информации.

А.Д. Иванова и О.В. Моругова построили критику онлайн-обучения на основе обсуждений в студенческих группах предложенного гайда и реакции на результаты этого обсуждения со стороны преподавательского сообщества. В итоге на каждый тезис студентов о качестве был получен антитезис преподавателей против качества. Тезис: «обучение в любом месте в удобное время»; антитезис: «такой подход выдает желание получить образование без реальных знаний, только ради диплома». Тезис: «индивидуальный темп, собственный график, выбор предметов самостоятельно»; антитезис: «студенты не знают, как взаимосвязаны предметы, какие из них им реально понадобятся». Тезис: «учиться 
без преподавателей психологически комфортнее»; антитезис: «за этой формулировкой скрывается незнание предмета и нежелание проверять свои реальные познания». Тезис: «онлайн-образование более экономичное и дешевое»; антитезис: «экономия на образовании ведет к снижению его качества»; тезис: «онлайн-образование позволит избавиться от “слабых" преподавателей»; антитезис: «в результате искусственно созданной конкуренции останутся только преподаватели, которые лучше владеют информационными ресурсами или располагают административным ресурсом, что вовсе не означает их более высокий профессионализм по специальности». Помимо этой дихотомии, авторы приводят и однозначные тезисы, препятствующие достижению качества образования в условиях онлайн-обучения. К их числу относятся: неспособность электронного обучения обеспечить изучение сложных теоретических проблем; отсутствие вовлеченности в образовательный процесс при просмотре лекций в записи; невозможность вносить изменения в уже записанный видеоматериал, тогда как лекции, читаемые в традиционном формате, обновляются по мере необходимости; отсутствует обратная связь между студентами и преподавателями; невозможность проведения полноценных практических занятий; исчезает соперничество как один из главных мотивов обучения; не формируются навыки публичных выступлений; притупляется чувство социальности, группового взаимодействия; в ходе электронного обучения усугубляется феномен «клипового мышления»; становится более актуальной проблема психологического разобщения между людьми; настроиться на учебу вне аудитории может далеко не каждый студент; преподавателю трудно работать с полной отдачей, если он не чувствует аудиторию; у преподавателя уходит очень много времени на переписку со студентами, он превращается в подобие секретаря (в аудитории ответ на типичный вопрос слышит вся группа, что существенно сокращает время); онлайн-курсы быстро устаревают, особенно по общественным дисциплинам; онлайн-обучение приведет к деградации преподавательских кадров в региональных вузах и их полному подчинению московским университетам; онлайн-образование приведет к увеличению нагрузки на преподавателей; вместо системного знания студентов будут обучать знанию об источниках информации; онлайн-образование содействует расслабленности; чрезмерная визуализация деформирует способность достраивать картинку, представляет информацию как готовое знание, которое не нужно индивидуально перерабатывать и размышлять над ним [28].

Заключение. Оценка ресурсов онлайнобучения в контексте их использования как возможностей достижения качества высшего образования позволила выделить три направления, в рамках которых имеются принципиальные различия, имеющие следующие проявления: 1) приемлемое качество высшего образования можно обеспечить в режиме онлайн-обучения уже сейчас; 2) качество образования можно обеспечить в будущем при решении ряда проблемных вопросов, возникающих в настоящее время в ходе образовательного процесса при онлайн-обучении; 3)качество обучения в режиме онлайн уступает классическому, т.к. имеет ограниченный объем ресурсов.

Подводя общий итог сложившемуся дискурсу, можно отметить, что несмотря на широкую представленность большим количеством подходов и направлений, он содержит целый ряд лакун, без заполнения которых невозможно решить вопрос о ресурсах онлайн-обучения в достижении качества образования в высшей школе. Прежде всего, это отсутствие внятной дефиниции онлайн-обучения, недостаточно ясное понимание того, на какие виды оно распадается в реальных образовательных практиках и на каком уровне качества эти виды онлайн-обучения способны поддерживать образовательный процесс в высшей школе.

\section{Литература}

1. Miri Barak, Abeer Watted, Hossam Hai$c k$. Motivation to learn in massive open online courses: Examining aspects of language and social engagement // Computers \& Education. 2016. - №94. - P. 49-60.

2. Kizilcec R. F., Schneider E. Motivation as a Lens to Understand Online Learners // ACM Transactions on Computer-Human Interaction 22, 2. - Article 6 (March 2015). - 24 p. 
3. Watters A. The MOOC Revolution that was not // The Daily Spot. - August 23, 2015. - P. 2-3.

4. ClarkP. Academics are Down on MOOCs. Business Schools Aren't [Electronic resource]. - URL: http://www.businessweek. com/articles/2014-01-16/academics-are-downon moocs-business-schools-arent/ (Date accessed: 02.02.2014).

5. Admiraal $W$., Huisman B., Pilli O. Assessment in massive open online courses // The Electronic Journal of e-Learning. - 2015. Vol. 13. - Issue 4. - Pp. 207-216.

6. Тимкин С.Л. Открытые образовательные ресурсы: международное сотрудничество образовательных учреждений // Открытое и дистанционное образование. - 2013. №1. - С. 55-59.

7. Тимкин С.Л. МООК и экономика образования в США. Теория подрывных инноваций применительно к МООК и ее критика. Екатеринбург: УФУ, 2014. - С. 1345-1354.

8. Тимкин С.Л. Дискуссия о термине и смысле электронного университета: выводы для ассоциации ОМРЭУ. - Омск: КАН, 2014. - C. 334-341.

9. Андреев А. А., Солдаткин В. И. Дистанционное обучение и дистанционные образовательные технологии // Cloud of science. 2013. - №1. - C. 14-20.

10. Бадарч Д., Токарева Н.Г., Цветкова М.C. МООК: реконструкция высшего образования // Высшее образование в России. - 2014. - №10. - С. 135-146.

11. Лапчик М.П. Тернистый путь электронных технологий в образовании // Информатика и образование. - 2014. - №8. - С. 3-11.

12. Зинченко В.П. Дистанционное образование: к постановке проблемы // Педагогика. - 2000. - №2. - С. 23-30.

13. Паспорт «Современная цифровая образовательная среда в Российской Федерации»/ Утв. Президиумом Совета при Президенте РФ по стратегическому развитию и приоритетным проектам // СПС КонсультантПлюс.

14. Гюль Д. В. Онлайн-образование в России: препятствия и перспективы / Юбилейный сборник научных трудов преподавателей, аспирантов и магистрантов социологического факультета Самарского государственного университета. - Самара: СГУ, 2014. - C. 100-109.
15. Кряклина Т. Ф., Реттих С. В. Massive open online courses - массовые открытые онлайн курсы в высшем образовании // Академик. - 2018. - №1. - С. 26-33.

16. Смирнова А.А. Образовательные онлайн-платформы как явление современного мирового образования: к определению понятия // Искусственные общества. - 2019. T. 14. 一 №1. - С. 8.

17. Гречушкина Н.В. Онлайн-курсы как средство кастомизации подготовки специалистов в образовательном процессе вуза / Высшая школа: проблемы и перспективы. Минск: АУЛ, 2019. - С. 20-22.

18. Базылевич A. В. Оценка качества онлайн-образования / Глобализация и интеграция исследований в практическую деятельность. - СПб.: ЕНМЦ «Мультидисциплинарные исследования», 2020. - С. 57-60.

19. Рощина Я.М., Рощчи С.Ю., Рудаков В.Н. Спрос на массовые открытые онлайн-курсы (МOOC) // Вопросы образования. - 2018. — №1. - С. 174-199.

20. Костюк Ю. Л., Левин И. С., Фукс А.Л., Фукс И.Л., Янковская А.Е. Массовые открытые онлайн-курсы - современная концепция в образовании и обучении // Вестник Томского государственного университета. Управление, вычислительная техника и информатика. - 2014. - №1. - С. 89-98.

21. Ольшанникова Н.А. Новые формы высшего образования с использованием современных онлайн-технологий // Профессиональное образование в современном мире. 2020. - T. 10. - №2. - C. 3688-3694.

22. Ибодова С.К. Онлайн-обучение в условиях пандемии: вызовы и перспективы // Аллея науки. - 2020. - №7. - C. 820-826.

23. Гулая T.M. Массовые открытые онлайн-курсы (MOOCS) - новое направление развития высшего образования: возможности, проблемы, перспективы // Сборники конференций НИЦ Социосфера. - 2014. №19. - С. 44-50.

24. Кузнецов Н. В. Всеобщая цифровизация и социальные риски // Общество: политика, экономика, право. - 2020. - №10. - С. 42-47.

25. Кузнецов Н.В. Онлайн-образование: ключевые тренды и препятствия // E-Management. - 2019. - T. 2. — №1. - C. 19-25.

26. Касьянов В.В., Самьгин С.И., Мухина К. С. Кризис высшего образования в Рос- 
сии и депрофессионализация студентов // Гуманитарные, социально-экономические и общественные науки. - 2020. - №5. С. 59-63.

27. Ковалев В.В., Дятлов А.В., Воденко K. B. Оценка качества онлайн-образования (по материалам фокусированных интервью в студенческих группах) // Вестник ЮжноРоссийского государственного технического университета (Новочеркасского политехнического института). - 2020. - Т. 13. №3. - С. 6-14.

28. Иванова А.Д., Муругова О.В. Онлайнобразование глазами студентов и преподавателей // Открытое образование. - 2020. T. 24. 一 №2. - C. 4-16.

\section{References}

1. Miri Barak, Abeer Watted, Hossam Hai$c k$. Motivation to learn in massive open online courses: Examining aspects of language and social engagement // Computers \& Education. 2016. — №94. — P. 49-60.

2. Kizilcec R.F., Schneider E. Motivation as a Lens to Understand Online Learners // ACM Transactions on Computer-Human Interaction 22, 2. - Article 6 (March 2015). - 24 p.

3. Watters $A$. The MOOC Revolution that was not // The Daily Spot. - August 23, 2015. - P. 2-3.

4. Clark P. Academics are Down on MOOCs. Business Schools Aren't [Electronic resource]. - URL: http://www.businessweek. com/articles/2014-01-16/academics-are-downon moocs-business-schools-arent/ (Date accessed: 02.02.2014).

5. Admiraal W., Huisman B., Pilli O. Assessment in massive open online courses // The Electronic Journal of e-Learning. - 2015. Vol. 13. - Issue 4. - Pp. 207-216.

6. Timkin S.L. Otkrytye obrazovatel'nye resursy: mezhdunarodnoe sotrudnichestvo obrazovatel'nyh uchrezhdenij [Open educational resources: international cooperation of educational institutions] // Otkrytoe i distancionnoe obrazovanie [Open and distance education]. 2013. — №1. - Pp. 55-59.

7. Timkin S. L. MOOK i jekonomika obrazovanija v SShA. Teorija podryvnyh innovacij primenitel'no $\mathrm{k}$ MOOK i ee kritika [MOOC and the economics of education in the USA.
The theory of disruptive innovation in relation to MOOCs and its criticism]. - Ekaterinburg: UFU, 2014. - Pp. 1345-1354.

8. Timkin S. L. Diskussija o termine i smysle jelektronnogo universiteta: vyvody dlja associacii OMRJeU [Discussion about the term and meaning of the electronic university: conclusions for the Association of OMREU]. - Omsk: KAN, 2014. - Pp. 334-341.

9. Andreev A.A., Soldatkin V.I. Distancionnoe obuchenie i distancionnye obrazovatel'nye tehnologii [Distance learning and distance educational technologies] // Cloud of science. 2013. - №1. - Pp. 14-20.

10. Badarch D., Tokareva N.G., Cvetkova M.S. MOOK: rekonstrukcija vysshego obrazovanija [MOOC: reconstruction of higher education] // Vysshee obrazovanie v Rossii [Higher education in Russia]. — 2014. - №10. Pp. 135-146.

11. Lapchik M.P. Ternistyj put' jelektronnyh tehnologij v obrazovanii [Thorny path of electronic technologies in education] // Informatika i obrazovanie [Computer science and Education]. - 2014. - №8. - Pp. 3-11.

12. Zinchenko V.P. Distancionnoe obrazovanie: $\mathrm{k}$ postanovke problemy [Distance education: to the formulation of the problem] // Pedagogika [Pedagogy]. - 2000. — №2. - Pp. 23-30.

13. Pasport «Sovremennaja cifrovaja obrazovatel'naja sreda v Rossijskoj Federacii» [Passport «Modern digital educational environment in the Russian Federation»] / Utv. Prezidiumom Soveta pri Prezidente RF po strategicheskomu razvitiju i prioritetnym proektam [Approved the Presidium of the presidential Council of the Russian Federation for strategic development and priority projects] // SPS Konsul'tantPljus.

14. Gjul' D. V. Onlajn-obrazovanie v Rossii: prepjatstvija i perspektivy [Online education in Russia: obstacles and prospects] / Jubilejnyj sbornik nauchnyh trudov prepodavatelej, aspirantov i magistrantov sociologicheskogo fakul'teta Samarskogo gosudarstvennogo universiteta [Jubilee collection of scientific works of teachers, postgraduates and undergraduates of the Faculty of Sociology of Samara State University]. - Samara: SGU, 2014. — Pp. 100-109.

15. Krjaklina T.F., Rettih S. V. Massive open online courses - massovye otkrytye onlajn kursy v vysshem obrazovanii [Massive open on- 
line courses-mass open online courses in higher education] // Akademik. — 2018. - №1. Pp. 26-33.

16. Smirnova A.A. Obrazovatel'nye onlajnplatformy kak javlenie sovremennogo mirovogo obrazovanija: $\mathrm{k}$ opredeleniju ponjatija [Educational online platforms as a phenomenon of modern world education: to the definition of the concept] // Iskusstvennye obshhestva [Artificial societies]. - 2019. - Vol. 14. — №1. - P. 8.

17. Grechushkina N.V. Onlajn-kursy kak sredstvo kastomizacii podgotovki specialistov $\mathrm{v}$ obrazovatel'nom processe vuza [Online courses as a means of customizing the training of specialists in the educational process of the university] / Vysshaja shkola: problemy i perspektivy [Higher School: problems and prospects]. Minsk: AUL, 2019. - Pp. 20-22.

18. Bazylevich A.V. Ocenka kachestva onlajn-obrazovanija [Evaluation of the quality of online education] / Globalizacija i integracija issledovanij v prakticheskuju dejatel'nost' [Globalization and the integration of research into practice]. - Saint Petersburg: ENMC «Mul'tidisciplinarnye issledovanija», 2020. Pp. 57-60.

19. Roshhina Ja. M., Roshhin S. Ju., Rudakov V.N. Spros na massovye otkrytye onlajn-kursy (MOOC) [The demand for massive open online courses (MOOCS) in education]// Voprosy obrazovanija [Education issues]. — 2018. — №1. Pp. 174-199.

20. Kostjuk Ju. L., Levin I.S., Fuks A.L., Fuks I.L., JankovskajaA.E. Massovye otkrytye onlajn-kursy - sovremennaja koncepcija $\mathrm{v}$ obrazovanii $\mathrm{i}$ obuchenii [Mass open online courses - a modern concept in education and training] // Vestnik Tomskogo gosudarstvennogo universiteta. Upravlenie, vychislitel'naja tehnika i informatika [Bulletin of Tomsk State University. Management, computer engineering and Computer Science]. — 2014. — №1. — Pp. 89-98.

21. Ol'shannikova N.A. Novye formy vysshego obrazovanija s ispol'zovaniem sovremennyh onlajn-tehnologij [New forms of higher education with the use of modern online technologies] // Professional'noe obrazovanie v sovremennom mire [Professional education in the modern world]. — 2020. — Vol. 10. — №2. Pp. 3688-3694.

22. Ibodova S. K. Onlajn-obuchenie v uslovijah pandemii: vyzovy i perspektivy [Online education in the context of a pandemic: challenges and prospects] // Alleja nauki. - 2020. №7. - Pp. 820-826.

23. Gulaja T.M. Massovye otkrytye onlajnkursy (MOOCS) - novoe napravlenie razvitija vysshego obrazovanija: vozmozhnosti, problemy, perspektivy [Mass open online courses (MOOCS) - a new direction in the development of higher education: opportunities, problems, prospects] // Sborniki konferencij NIC Sociosfera. - 2014. — №19. - Pp. 44-50.

24. Kuznecov N. V. Vseobshhaja cifrovizacija i social'nye riski [Universal digitalization and social risks] // Obshhestvo: politika, jekonomika, pravo [Society: politics, economics, law]. 2020. — №10. - Pp. 42-47.

25. Kuznecov N.V. Onlajn-obrazovanie: kljuchevye trendy i prepjatstvija [Online education: key trends and barriers] // E-Management. - 2019. — Vol. 2. — №1. - Pp. 19-25.

26. Kas'janov V. V., Samygin S.I., Muhina K.S. Krizis vysshego obrazovanija v Rossii i deprofessionalizacija studentov [The crisis of higher education in Russia and the deprofessionalization of students] // Gumanitarnye, social'no-jekonomicheskie i obshhestvennye nauki [Humanities, socio-economic and social sciences]. - 2020. - №5. - Pp. 59-63.

27. Kovalev V.V., Djatlov A.V., Vodenko K.V. Ocenka kachestva onlajn-obrazovanija (po materialam fokusirovannyh interv'ju $\mathrm{v}$ studencheskih gruppah) [Assessment of the quality of online education (based on the materials of focused interviews in student groups)] // Vestnik Juzhno-Rossijskogo gosudarstvennogo tehnicheskogo universiteta (Novocherkasskogo politehnicheskogo instituta) [Bulletin of the South Russian State Technical University (Novocherkassk Polytechnic Institute)]. 2020. - Vol. 13. — №3. - Pp. 6-14.

28. Ivanova A.D., Murugova O.V. Onlajnobrazovanie glazami studentov i prepodavatelej [Online education through the eyes of students and teachers] // Otkrytoe obrazovanie [Open education]. — 2020. — Vol. 24. — №2. — Pp. 4-16. 


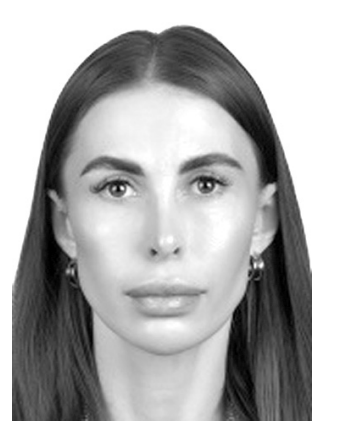

Лацвеева Александра Владимировна - аспирант ЮжноРоссийского государственного политехнического университета (НПИ) имени М.И. Платова.

Latsveeva Alexandra Vladimirovna - Postgraduate student, Platov South Russian State Polytechnic University (NPI).

346428 , г. Новочеркасск, ул. Просвещения, 132

132 Prosveshcheniya st., 346428, Novocherkassk, Russia

E-mail: iluxin.2011@mail.ru 